\title{
Assembly of carbon nanotubes on a nanoporous gold electrode for acetylcholinesterase biosensor design
}

\author{
Jiawang Ding ${ }^{\mathrm{a}}$, Hongxia Zhang ${ }^{\mathrm{a}}$, Falong Jia ${ }^{\mathrm{b}}$, Wei Qin ${ }^{\mathrm{a}, *}$, Dan $^{\mathrm{D}} \mathrm{Du}^{\mathrm{b}, * *}$ \\ ${ }^{a}$ Key Laboratory of Coastal Environmental Processes and Ecological Remediation, Yantai Institute of Coastal Zone Research (YIC), Chinese Academy of \\ Sciences (CAS), Shandong Provincial Key Laboratory of Coastal Environmental Processes, YICCAS, Yantai, Shandong 264003, PR China \\ ${ }^{\mathrm{b}}$ Key Laboratory of Pesticide \& Chemical Biology of Ministry of Education, Huazhong Normal University, Wuhan 430079, PR China
}

\section{A R T I C L E I N F O}

\section{Article history:}

Received 14 December 2013

Received in revised form 7 April 2014

Accepted 7 April 2014

Available online 18 April 2014

\section{Keywords:}

Nanoporous gold

Carbon nanotubes

Amperometry

Acetylcholinesterase

Pesticides

\begin{abstract}
A B S T R A C T
An electrochemical sensing platform based on assembly of carbon nanotubes on a nanoporous gold electrode is described for highly sensitive detection of organophosphate pesticides. The nanoporous gold film (NPG) electrode is fabricated by an alloying/dealloying process, which possess high electroactive surface area and is an excellent substrate for sensor design. The NPG functionalized with cysteamine allows the immobilization of carbon nanotubes on the electrode with the self-assembly technique. The carboxylated carbon nanotubes are further linkered with acetylcholinesterase (AChE) for amperometric sensing of pesticides. The immobilized AChE, as a model, shows excellent activity to its substrate and allows a quantitative measurement of organophosphate pesticides. Under the optimal experimental conditions, the inhibition of malathion is proportional to its concentration in the range of $0.001-0.5 \mu \mathrm{g} \mathrm{mL}^{-1}$ with a detection limit of $0.5 \mathrm{ng} \mathrm{mL}-1$. The proposed method shows good reproducibility and high stability, which provides a new avenue for electrochemical biosensor design.
\end{abstract}

(c) 2014 Elsevier B.V. All rights reserved.

\section{Introduction}

Over the past decades, nanoporous materials have attracted much attention for applications in catalysis, separation, sensors and actuators [1-3]. Among these materials, nanostructured gold films are of special interest because of the excellent stability and biocompatibility of gold for use in sensors and reactors [4]. Nanostructured gold films have a unique porous structure, high specific surface area, good permeability and high conductivity, which offer a large number of adsorption sites for proteins and enzymes and could increase the signal-to-noise ratio in the miniaturization systems [5]. Additionally, the porous structure has the ability to perform electrochemical measurements even in biofouling solutions [6]. Moreover, gold is an excellent substrate for formation of self-assembled monolayers (SAMs) with thiol, sulfide and disulfide groups. Such SAM can be used as an intermediate layer for coupling of a wide range of molecules such as enzymes, DNA and antibiotics [7].

\footnotetext{
* Corresponding author. Tel.: +865352109156.

** Corresponding author.

E-mail addresses: wqin@yic.ac.cn (W. Qin), dan.du@mail.ccnu.edu.cn (D. Du).
}

The striking properties of the nanoporous gold have motivated intensive interest in their utilization in biosensor designs. To date, a number of enzymes or large biomolecules (such as DNA and antibody) have been entrapped in or directly immobilized onto the nanoporous structure for sensitive detection [8]. However, the nanoporous gold electrode employed as a substrate for biosensor design via surface grafting of nanomaterials has not yet been reported. Moreover, the sensitivity and stability of the biosensors using nanoporous gold film needs to be improved [7].

Carbon nanotubes (CNTs) represent one kind of carbon-based materials that pocess unique structural and electronic features and are frequently used in electrochemistry [9]. Up to now, CNTs have been widely used in biosensor designs and nanoscale electronic devices owing to their ability to mediate electron-transfer reactions with enzymes and other biomolecules [10-12]. Moreover, CNTs provide an extremely large surface area for biomolecular conjugation and subsequent signal amplification [13]. In addition, shortened CNTs can be aligned to an electrode by self-assembly and be used to enhance the electron-transfer reaction with electroactive species [14]. Herein, multiwall carbon nanotubes (MWCNTs) are grafted onto porous gold via the self-assembled monolayer of cysteamine and used as a template for enzyme loading. CNTs play an important role in both the enzyme immobilization and 


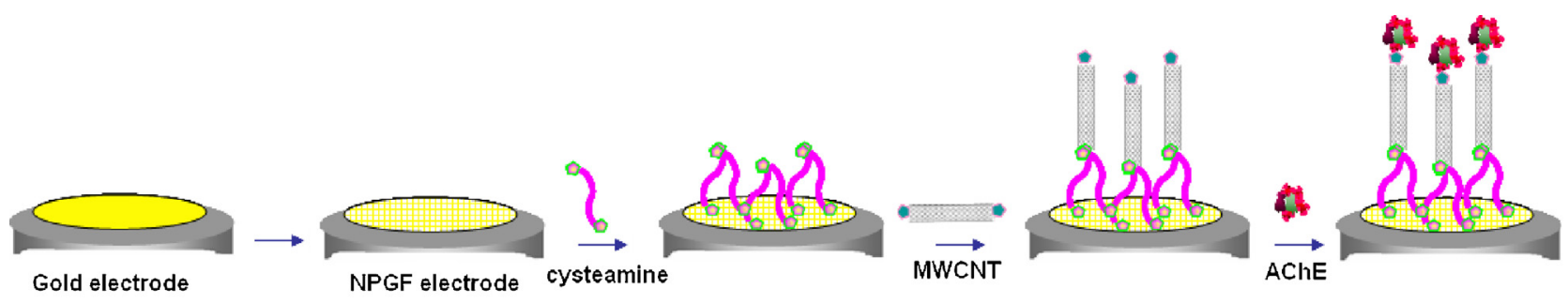

Fig. 1. Schematic illustration of the formation of AChE-MWCNT-CA-NPG.

transduction events. Combining the advantages of nanoporous gold with unique electrochemical properties of CNTs, it is possible to design an amperometric biosensor with good electron transfer properties and a high sensitivity.

Acetylcholinesterase (AChE), which is an essential enzyme responsible for the nervous system functioning and also a major target enzyme of organophosphorus and carbamate pesticides, is selected as a model. With AChE immobilized on the MWCNTs, its interaction with the substrate (acetylthiocholine) produces an electroactive product (thiocholine). The inhibition by organophosphate pesticides in the enzyme system can be monitored by measuring the oxidation current of thiocholine [15-19]. Based on the inhibition of AChE activity, a highly sensitive amperometric biosensor for pesticide was developed.

\section{Experimental}

\subsection{Chemicals}

Acetylthiocholine chloride (ATCl) and acetylcholinesterase (Type C3389, 500 $\mathrm{U} \mathrm{mg}^{-1}$ from electric eel), cysteamine (CA), 1-ethyl-3-(3-dimethylaminopropyl) carbodiimide (EDC), Nhydroxysuccinimide (NHS) and N,N-dimethylformamide (DMF) were purchased from Sigma and used as received. Malathion was obtained from AccuStandard (USA). Multiwall carbon nanotubes were obtained from the Institute of Nanometer, Huazhong Normal University. Phosphate buffer solution (PBS, $0.02 \mathrm{M} \mathrm{pH} 7.0$ ) was prepared with doubly distilled water. All other reagents were of analytical reagent grade.

\subsection{Apparatus}

Electrochemical measurements were performed on CHI-660C workstation (Chenhua Instruments Co., Shanghai, China) with a conventional three-electrode system comprised of a platinum wire as the auxiliary electrode, a saturated calomel electrode (SCE) as the reference, and a modified electrode as the working electrode. The ac impedance experiment was carried out in $5 \mathrm{mM} \mathrm{Fe}(\mathrm{CN})_{6}{ }^{4-13-}$ with frequencies ranging from $100 \mathrm{kHz}$ to $0.1 \mathrm{~Hz}$.

\subsection{Preparation of the nanoporous gold film electrode}

The gold electrode ( $3 \mathrm{~mm}$ in diameter) was polished, cleaned by acetone, alcohol and doubly distilled water and dried before use. Nanoporous gold film electrodes were prepared through multicyclic electrochemical alloying/dealloying processes in a novel electrolyte composed of $\mathrm{ZnCl}_{2}$ and benzyl alcohol according to the method described before [3,5]. The alloying/dealloying processes were carried out in the potential range of 1.8 to $-0.8 \mathrm{~V}$ ( $\mathrm{vs} \mathrm{Zn}$ ) with a scan rate of $10 \mathrm{mV} \mathrm{s}^{-1} .25$ cycles were applied to the gold working electrode using the electrochemical workstation with a $\mathrm{Zn}$ plate as the auxiliary electrode, and a $\mathrm{Zn}$ wire as the reference electrode. Before each experiment, the NPG electrode was cleaned in a $0.5 \mathrm{M}$
$\mathrm{H}_{2} \mathrm{SO}_{4}$ solution by the cyclic scan from 0.4 to $1.5 \mathrm{~V}$ (vs SCE) until reproductive curves were obtained.

\subsection{Fabrication of the acetylcholinesterase biosensor}

MWCNTs were first carboxyl-functionalized and shortened by reflux in $\mathrm{HNO}_{3}$ for $10 \mathrm{~h}$. The mixture was filtered, washed with water, and then dried and dispersed in DMF. The dispersion was then mixed with $1 \mathrm{~mL}$ of $300 \mathrm{mM}$ EDC and $35 \mathrm{mM}$ NHS in a $\mathrm{pH}$ 7.0 PBS buffer and vortexed at room temperature for $15 \mathrm{~min}$. The resulting mixture was centrifuged at $15,000 \mathrm{rpm}$ for $5 \mathrm{~min}$, and the supernatant was discarded. The excess EDC was removed by washing with buffer. The functionalized MWCNTs were resuspended in PBS buffer.

The nanoporous gold was immersed in $1 \mathrm{mM}$ cysteamine overnight to prepare the cysteamine modified electrode (CA-NPG). The CA-NPG electrode was placed in the nanotube solution for $4 \mathrm{~h}$ so that the amines at the terminus of the SAM formed amide bonds with one end of the tubes (MWCNT-CA-NPG). After that, $5.0 \mu \mathrm{L}$ AChE solution ( $100 \mathrm{mU}$ ) was dropped onto the modified electrode and dried in air at room temperature for another $2 \mathrm{~h}$ to obtain the AChE-MWCNT-CA-NPG. The electrode was washed with PBS twice to remove the AChE that was non-specifically bound (Fig. 1).

\subsection{Measurement procedures}

The AChE-MWCNT-CA-NPG electrode was first incubated in the PBS solution containing different concentrations of a standard organophosphate pesticide for $12 \mathrm{~min}$, and then transferred to the electrochemical cell of $1.0 \mathrm{~mL} \mathrm{pH} \mathrm{7.0} \mathrm{PBS} \mathrm{containing} 0.2 \mathrm{mM} \mathrm{ATCl}$ to record the amperometric signals. The inhibition of the organophosphate pesticde was calculated as follows [16]:

Inhibition $(\%)=100 \% \times \frac{i_{P, \text { control }}-i_{P, \exp }}{i_{P, \text { control }}}$

where $i_{P, \text { control }}$ and $i_{P, \exp }$ are the peak currents of thiocholine with and without organophosphate inhibition, respectively.

\section{Results and discussion}

\subsection{Estimation of the active surface area of the electrode}

The electrochemically active surface area is an important factor for potential applications of nanoporous materials. In this work, the surface area of the porous gold was determined first by integrating the reduction peak area of oxidized gold layer formed by cyclic voltammetry (CV) scans from -0.2 to $+1.6 \mathrm{~V}$ in $0.5 \mathrm{M} \mathrm{H}_{2} \mathrm{SO}_{4}[20,21]$. The average value of the electroactive surface area of the electrode can be calculated according to the Randles-Sevcik equation [22]. The surface area of the porous gold was calculated to be $0.24 \mathrm{~cm}^{2}$, while that of the bare gold electrode was $0.05 \mathrm{~cm}^{2}$. By integrating the charge consumed in the gold oxide reduction, the roughness factor can be obtained [5]. The roughness factor increased from 1.5 

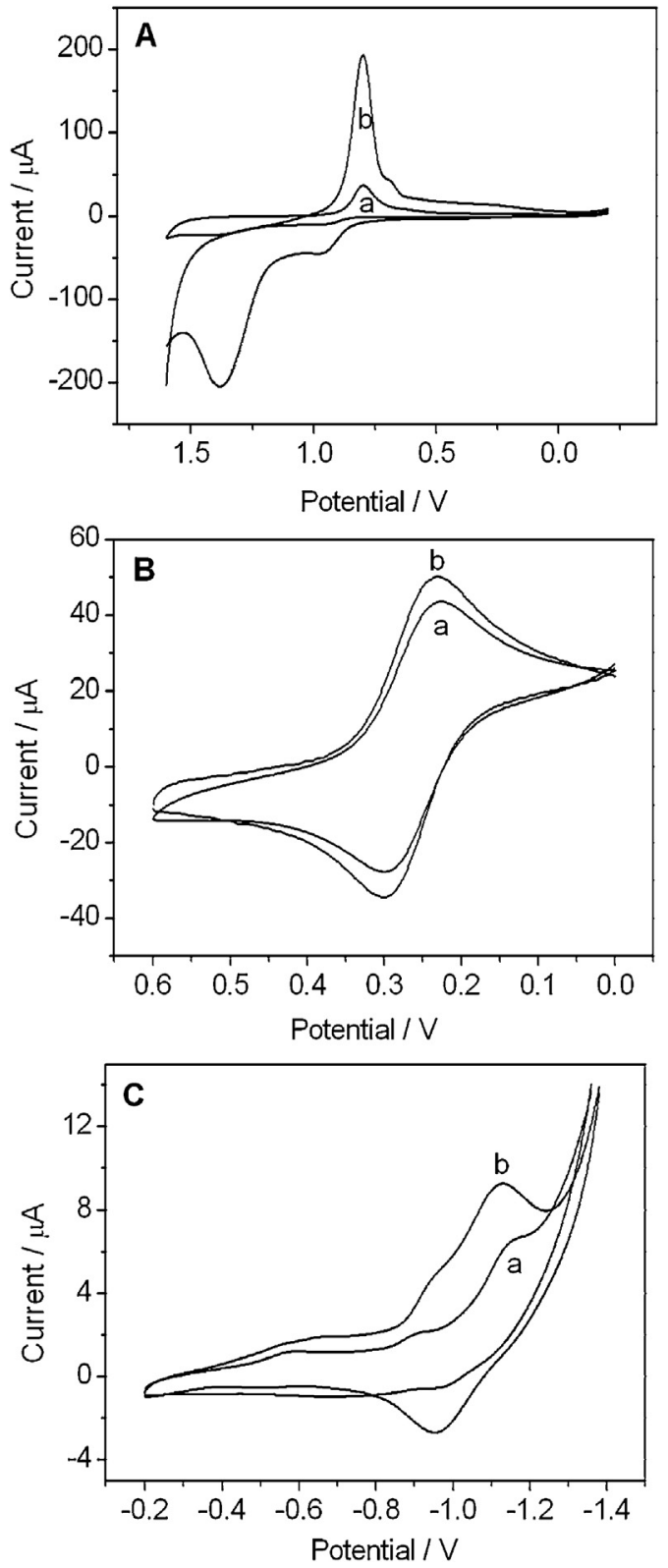

Fig. 2. CV curves recorded in (A) $0.5 \mathrm{M} \mathrm{H}_{2} \mathrm{SO}_{4}$, (B) $5.0 \mathrm{mM} \mathrm{Fe}(\mathrm{CN})_{6}{ }^{4-/ 3-}$ for (a) the polished gold electrode and (b) the nanoporous gold electrode, and (C) $0.5 \mathrm{M} \mathrm{KOH}$ for (a) the polished gold electrode and (b) the nanoporous gold electrode after being immersed in cystamine for $12 \mathrm{~h}$. The scan rate was $50 \mathrm{mV} \mathrm{s}^{-1}$.

of the bare gold electrode to 7.5 of the porous gold (Fig. 2A). The active surface area was 5 -fold higher than that of the bare gold.

$\mathrm{Fe}(\mathrm{CN})_{6}{ }^{4-/ 3-}$ as one of the most extensively studied redox couples in electrochemistry was further used to confirm the properties and changes of the porous surface. When this couple is used on a flat electrode, a linear increase of the signal as a function of the active surface area, usually proportional to the geometric area, can be observed. Unlike the flat electrode, the porous one does not show such a behavior for a given geometric area (Fig. 2B). The active surface area of the porous gold is only 1.2-fold higher than that of the bare gold. Due to the high reaction rate of the $\mathrm{Fe}(\mathrm{CN})_{6}{ }^{4-13-}$ redox couple, the molecules react completely at the outermost pore before they are able to diffuse into the inner pores, thus only a small part of the whole active area is used for the reaction $[23,24]$. Although the advantage of the NPG electrode could not fully stand out on analyzing redox reactions with fast electron-transfer

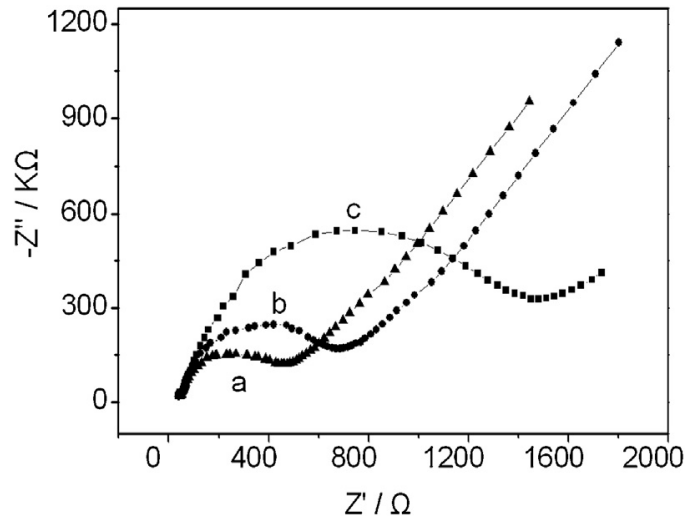

Fig. 3. EIS for (a) MWCNT-CA-NPG, (b) CA-NPG and (c) AChE-MWCNT-CA-NPG in $10 \mathrm{mM}$ pH 7.4 PBS containing $5.0 \mathrm{mM} \mathrm{Fe}(\mathrm{CN})_{6}{ }^{4-/ 3-}$ and $0.1 \mathrm{M} \mathrm{KCl}$.

kinetics, we expect that a remarkable increase in electrochemical signal at the NPG electrode could be observed for redox reactions with low electron-transfer kinetics.

The electrochemical behavior of monolayers of cysteamine chemisorbed on the surface of porous gold was investigated. The NPG electrode was immersed in $1 \mathrm{mM}$ cysteamine overnight to prepare the SAMs. The CA-NPG electrode was characterized by its reductive desorption peak of thiols. The cyclic voltammogram of a cysteamine modified gold electrode displays a reduction peak at $-1.11 \mathrm{~V}$ in $0.5 \mathrm{M} \mathrm{KOH}$ at $100 \mathrm{mV} \mathrm{s}^{-1}$ (Fig. 2C). This peak is attributed to the reductive desorption of the thiolated compounds bound to gold $[25,26]$, indicating the presence of the cysteamine molecules on the gold surface. From the integration of the reductive desorption peak, the surface coverage, $\Gamma(\Gamma=Q / n F A$, where $Q$ is the charge (C), $n$ is the number of transfer electrons, $F$ is the Faraday constant, and $A$ is the geometric area of the electrode), was calculated to be $2.3 \times 10^{-10} \mathrm{~mol} / \mathrm{cm}^{2}$. The coverage of bare gold was $1.3 \times 10^{-10} \mathrm{~mol} / \mathrm{cm}^{2}$. Therefore, the active surface area is 1.8 -fold higher than that of the bare gold, which indicates that more cysteamine SAM is accessible in the porous gold electrode. Since the pore cannot be fully occupied by cysteamine. The results obtained with the cysteamine reduction are smaller than those obtained with the gold oxide reduction.

\subsection{AC impedance measurements}

To check if the MWCNTs and AChE were formed on the surface, electrochemical impedance spectra (EIS) were used to characterize the resulting surface. As shown in Fig. 3, the electron transfer resistances of $\mathrm{Fe}(\mathrm{CN})_{6}{ }^{4-13-}$ at CA-NPG (curve a), MWCNTCA-NPG (curve b), and AChE-MWCNT-CA-NPG are 681, 454, and $1456 \Omega$, respectively. These results indicate that: the amines at terminus of the SAM form amide bonds with one end of the MWCNTs other activated sites of MWCNTs can be used to bond AChE. The decrease in the interfacial resistance of MWCNT-CA-NPG indicates that MWCNTs facilitate the electron transfer across selfassembled monolayers and act as molecular wires [9]. Moreover, the combination of nanoporous gold and MWCNTs yields better electron transfer properties. The significant change was observed for AChE-MWCNT-CA-NPG, indicating that the immobilized AChE layer induces a barrier to electrochemical process.

\subsection{Cyclic voltammetric behaviors of the biosensor}

Although AChE can be immobilized on the self-assembled monolayer of cysteamine, the previous report has shown that a number of active proteins can be immobilized on per CNT [27]. Therefore, CNTs could play an important role in both the 


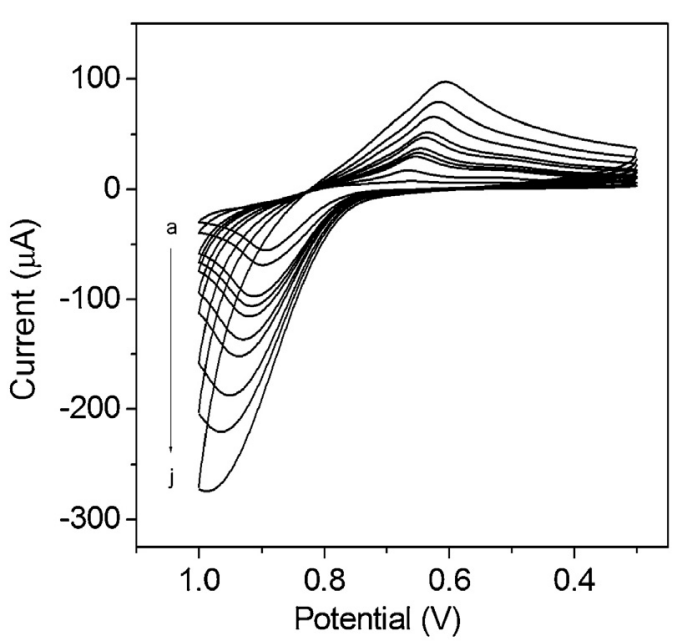

Fig. 4. Cyclic voltammograms of AChE-MWCNT-CA-NPG in pH 7.0 PBS containing $0.2 \mathrm{mM} \mathrm{ATCl}$ at different scan rates. (a) 10 , (b) 20, (c) 40, (d) 60, (e) 80, (f) 100, (g) 150, (h) 200, (i) 300 and (j) $400 \mathrm{mV} \mathrm{s}^{-1}$.

enzyme immobilization and signal amplification. Moreover, integrating carbon nanotubes (CNTs) with biological systems to form hybrid functional assemblies is promising in different fields such as nanotechnology, medicine, materials science, and biology [28]. In this article, AChE was selected as a model and immobilized on MWCNTs. The reaction between AChE-MWCNT-CA-NPG and the ATCl substrate is a CE (chemical and electrochemical) coupled reaction, including a chemical reaction: $\mathrm{EH}$ (enzyme)+ RS$\mathrm{COR}_{2}$ (substrate) $\rightarrow \mathrm{RSH}+\mathrm{E}-\mathrm{COR}_{2}$ and an electrode reaction: $\mathrm{RSH}-$ $2 \mathrm{e}^{-} \rightarrow \mathrm{RSSR}+2 \mathrm{H}^{+}[16]$. The effect of scan rate on peak current was examined. For the AChE-MWCNT-CA-NPG electrode, the peak current increases and the peak potential shifts slightly with increasing scan rate (Fig. 4). The peak currents exhibit a linear dependence on the scan rate ranging from 10 to $300 \mathrm{mV} \mathrm{s}^{-1}$, indicating a typical surface-controlled electrode process [16].

\subsection{Cyclic voltammetric behaviors of the AChE-MWCNT-CA-NPG electrode}

Experiments showed that no redox peaks were observed at MWCNT-CA-NPG (curve a) and at AChE-MWCNT-CA-NPG (curve b) in $\mathrm{pH} 7.0 \mathrm{PBS}$. In the presence of $0.2 \mathrm{mM} \mathrm{ATCl}$, an oxidation peak at $913 \mathrm{mV}$ was observed for the AChE-MWCNT-CA-NPG electrode (Fig. 5d), while no detectable signal was found for MWCNT-CA-NPG electrode (curve c). Obviously, this peak is caused by the oxidation

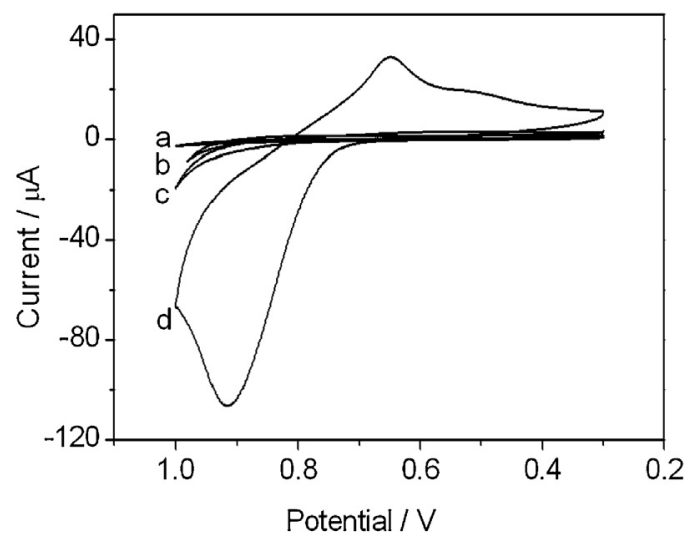

Fig. 5. Cyclic voltammograms of (a) MWCNT-CA-NPG, (b) AChE-MWCNT-CA-NPG in pH 7.0 PBS; (c) MWCNT-CA-NPG, (d) AChE-MWCNT-CA-NPG in pH 7.0 PBS containing $0.2 \mathrm{mM} \mathrm{ATCl}$. Scan rate: $50 \mathrm{mV} \mathrm{s}^{-1}$.

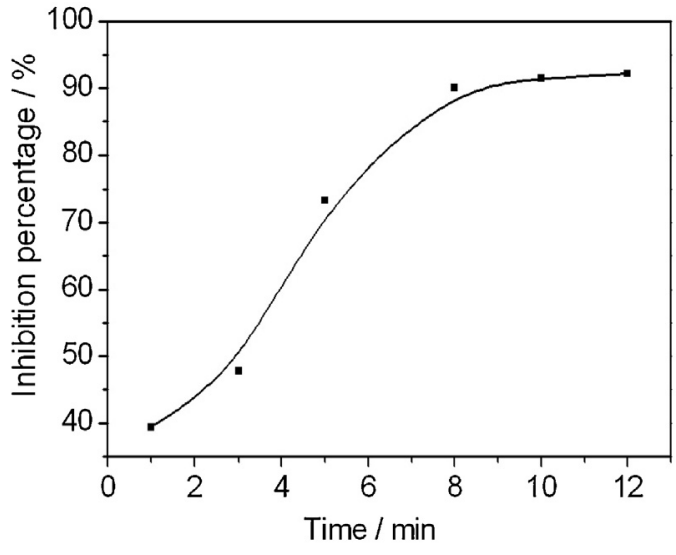

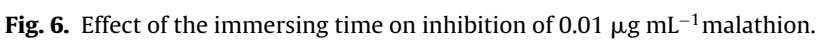

of thiocholine (the hydrolysis product of $\mathrm{ATCl}$ ), which is catalyzed by the immobilized AChE. AChE immobilized at the surface of the biosensor exhibits a fast response and high affinity to its substrate. The produced current by thiocholine can be used for quantification of the enzyme activity, which reflects the biological effect of an organophosphate pesticide involved in the inhibition action. The amount of ATCl directly influences the amount of reduced thiocholine, which changes the oxidative peak current. In this work, saturate amount of ATCl was used. It should be noted that the cyclic voltammogram of AChE-MWCNT-CA-NPG displayed a pair of peaks in the presence of ATCl (Fig. 5d). This phenomenon was also observed by others [29-31]. The cathodic peak might be attributed to the reduction of the thiocholine and the mechanism is currently being investigated.

\subsection{Effect of incubation time on the response of the AChE-MWCNT-CA-NPG electrode}

Incubation time is a very important parameter for enzymeinhibition based biosensing systems. For irreversible inhibition, a low detection limit can be obtained with a longer incubation time. When in contact with malathion, the produced current of ATCl on the AChE-MWCNT-CA-NPG electrode decreases drastically. The decrease in peak current is related to the increase in the incubation time (Fig. 6). When the incubation time is longer than $12 \mathrm{~min}$, the curve trends to a stable value, indicating the binding interaction with active target groups in enzyme reaches saturation. This change tendency of peak current reflects the alteration of enzymatic activity, which results in the change of the interaction with its substrate. However, the maximum value of inhibition of malathion is not $100 \%$, which is likely to attribute to the binding equilibrium between the pesticide and the binding sites in the enzyme.

\subsection{Calibration curve for malathion determination}

Due to the notable change in voltammetric signal of the AChEMWCNT-CA-NPG electrode, a simple method for determination of malathion can be established. It should be noted that the dissociation constant for the initial reversible enzyme inhibitorcomplex is ca $10^{-5} \mathrm{M}^{-1}$ [32]. Therefore, malathion may show a weak reversible inhibition at lower concentrations. However, there are malathion transformation products which are generally formed during storage or through natural or photochemical degradation. These impurities include OP esters that bear one thiolester ligand (P-S-R), the oxidation product malaoxon, and the isomerization product isomalathion. These impurities are far more potent anti-cholinesterase agents, which inhibit free and immobilized AChE in a concentration-dependent manner [32,33]. This 
Table 1

Comparison of analytical characteristics of amperometric AChE biosensors for malathion with the present biosensor.

\begin{tabular}{|c|c|c|c|c|}
\hline Electrode & Incubation time (min) & Linearity (nM) & Detection limit (nM) & Reference \\
\hline AchE/chitosan/Au & 10 & $0.3-15$ & 0.15 & [17] \\
\hline AchE/AuNPs- $\mathrm{CaCO}_{3} /$ silica sol-gel/Au & 10 & $0.1-100$ & 0.1 & [29] \\
\hline AchE/ZnS/Pin5COOH/Au & 10 & $0.1-50$ & 0.1 & [36] \\
\hline $\mathrm{AchE} / \mathrm{Fe}_{3} \mathrm{O}_{4} \mathrm{NPs} / \mathrm{c}-\mathrm{MWCNT} / \mathrm{ITO}$ & 10 & $0.1-40$ & 0.1 & [37] \\
\hline AchE $/ \mathrm{ZrO}_{2} /$ chitosan/GC & 15 & $10-59$ & 5 & [41] \\
\hline AchE/sol-gel/SPE & 10 & $10-500$ & 3.6 & [42] \\
\hline AchE/MWCNT/CA/NPG & 12 & $3-150$ & 1.5 & Present \\
\hline
\end{tabular}

phenomenon was also observed by others [34,35]. With increasing the malathion concentration, the produced current of $\mathrm{ATCl}$ on the AChE-MWCNT-CA-NPG electrode decreases (Fig. 7A). Under the optimal experimental conditions, the inhibition of malathion on the AChE-MWCNT-CA-NPG electrode is proportional to its concentration in the range of $0.001-0.5 \mu \mathrm{g} \mathrm{mL}-1$ with a correlation coefficient of 0.998 (Fig. 7B). The detection limit is $0.5 \mathrm{ng} \mathrm{mL}^{-1}$ taken as the concentration equivalent to a $10 \%$ decrease in signal. Recently, a number of AChE biosensors have been developed for malathion. However, the detection limits were calculated in different ways $[29,36,37]$. Our reported value is much lower or comparable to those in the references $[30,38]$. The inhibition rate of malathion decreased when increasing the concentration of malathion, indicating that the binding interactions between the pesticide and the enzyme could reach an equilibrium. In the presence of pesticide at high concentrations, the inhibition percentage change is not so pronounced [39]. So, two linear ranges on the calibration curve were observed. This phenomenon was also observed by others [40].
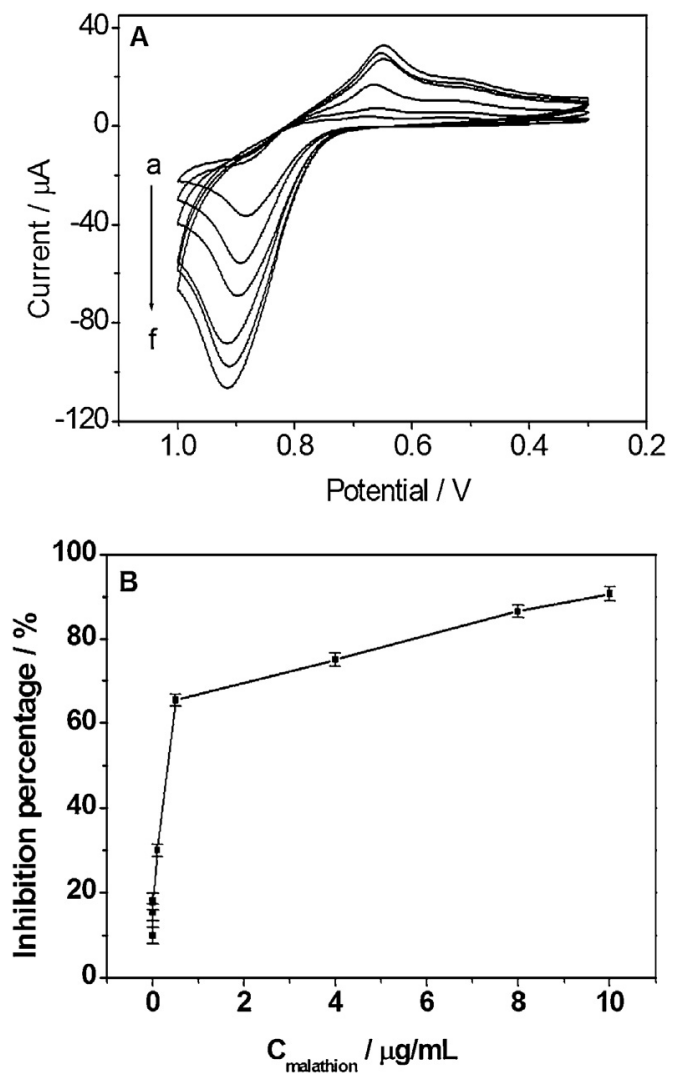

Fig. 7. (A) Cyclic voltammograms of AChE-MWCNT-CA-NPG in pH 7.0 PBS containing $0.2 \mathrm{mM}$ ATCl after immersed in (A) malathion solution with different concentrations of (a) 0 , (b) 0.001 , (c) 0.01 , (d) 0.1 , (e) 0.3 and (f) $0.5 \mu \mathrm{g} \mathrm{mL}^{-1}$. (B) Linear relationships between the inhibition percentage and malathion concentration . Error bars represent 1 standard deviation from three measurements.
So far, carbon nanotube-based nanocomposites have been widely used for acetylcholinesterase sensors. Unlike previous reports, shortened CNTs can be aligned to an electrode by selfassembly and be used to enhance the electron-transfer reaction with electroactive species [14]. The performance of this AChEMWCNT-CA-NPG compared with other reported AChE biosensors for malathion is summarized in Table 1. In our previous research, we reported an electrochemical sensor based on enzyme-induced growth of AuNPs [17]. The $\left[\mathrm{Fe}(\mathrm{CN})_{6}\right]^{3-/ 4-}$ redox system needs to be added and used as an additional reporter. Moreover, the method can only be used for a system including a reductant. Compared with that sensor, the present sensing platform is more general and can avoid the addition of other signal reporters. Since the oxidized form of malathion shows a stronger inhibitory effect toward AChE than unoxidized, an oxidative treatment of malathion can improve the detection limit further $[43,44]$.

\subsection{Reproducibility and stability of the AChE-MWCNT-CA-NPG electrode}

The inter-assay precision was estimated by determining the responses of $0.2 \mathrm{mM} \mathrm{ATCl}$ at five different electrodes. The enzyme electrodes were immersed in $0.1 \mu \mathrm{g} \mathrm{mL}^{-1}$ and $2.0 \mu \mathrm{g} \mathrm{mL}^{-1}$ malathion for $12 \mathrm{~min}$, respectively. The coefficients of variation were calculated to be $4.6 \%$ and $2.7 \%$, respectively. The intra-assay precision of the sensors was evaluated by assaying one enzyme electrode for five replicate measurements, and the RSD was 3.9\% at the $\mathrm{ATCl}$ concentration of $0.2 \mathrm{mM}$.

When the enzyme electrode was not in use, it was stored at $4{ }^{\circ} \mathrm{C}$ in dry conditions. No obvious decrease in the response to ATCl was observed for the first 5-day storage. After two weeks, the sensor retains $85 \%$ of initial current response to $\mathrm{ATCl}$. For practical applications, the interferences such as heavy metal ions should be taken into consideration. Since the AChE-based biosensor can be commonly used for the detection of most organophosphorous pesticides, the selectivity can be further improved by using organophosphorus hydrolase. Moreover, various mediators can be employed to lower the oxidation potential.

\section{Conclusions}

In summary, we have shown that multiwall carbon nanotubes (MWCNTs) can be linked to a nanoporous gold electrode by using the self-assembly technique. The MWCNTs can enhance the electron-transfer reaction with electroactive species generated from enzymatic reactions. In addition, many enzymes could be assembled on MWCNTs and used to amplify the detection signals. The immobilized AChE, as an enzyme model, shows excellent activity to its substrate and allows a quantitative measurement of organophosphate pesticide. By combining the advantages of nanoporous gold with unique electrochemical properties of CNTs, we believe that such a constructed interface has potential applications for fabrication of amperometric biosensors. 


\section{Acknowledgements}

This work was financially supported by the National Natural Science Foundation of China ( 21207156), the Science and Technology Project of Yantai (2012132), and the Taishan Scholar Program of Shandong Province (No. TS20081159).

\section{References}

[1] Y. Ding, M.W. Chen, J. Erlebacher, Metallic mesoporous nanocomposites for electrocatalysis, J. Am. Chem. Soc. 126 (2004) 6876-6877.

[2] K. Bonroy, J.M. Friedt, F. Frederix, W. Laureyn, S. Langerock, A. Campitelli, M. Sara, G. Borghs, B. Goddeeris, P. Declerck, Realization and characterization of porous gold for increased protein coverage on acoustic sensors, Anal. Chem. 76 (2004) 4299-4306.

[3] F.L. Jia, C.F. Yu, K.J. Deng, L.Z. Zhang, Nanoporous metal (Cu, Ag, $\mathrm{Au}$ ) films with high surface area: general fabrication and preliminary electrochemical performance, J. Phys. Chem. C 111 (2007) 8424-8431.

[4] S. Sotiropoulou, V. Vamvakaki, N.A. Chaniotakis, Stabilization of enzymes in nanoporous materials for biosensor applications, Biosens. Bioelectron. 20 (2005) 1674-1679.

[5] F.L. Jia, C.F. Yu, Z.H. Ai, L.Z. Zhang, Direct oxidation of methanol on selfsupported nanoporous gold film electrodes with high catalytic activity and stability, Chem. Mater. 19 (2007) 6065-6067.

[6] J. Patel, L. Radhakrishnan, B. Zhao, B. Uppalapati, R.C. Daniels, K.R. Ward, M.M. Collinson, Electrochemical properties of nanostructured porous gold electrodes in biofouling solutions, Anal. Chem. 85 (2013) 11610-11618.

[7] L.T. Zheng, Y.L. Wei, H.Q. Gong, L. Qian, Application progress of nanoporous gold in analytical chemistry, Chin. J. Anal. Chem. 41 (2013) 137-144.

[8] T.J. Li, F.L. Jia, Y.X. Fan, Z.F. Ding, J. Yang, Fabrication of nanoporous thin-film working electrodes and their biosensing applications, Biosens. Bioelectron. 42 (2013) 5-11.

[9] L. Su, F. Gao, L.Q. Mao, Electrochemical properties of carbon nanotube (CNT) film electrodes prepared by controllable adsorption of CNTs onto an alkanethiol monolayer self-assembled on gold electrodes, Anal. Chem. 78 (2006) 2651-2657.

[10] L.B. Hu, D.S. Hecht, G. Grüner, Carbon nanotube thin films: fabrication, properties, and applications, Chem. Rev. 110 (2010) 5790-5844.

[11] M.G. Zhang, W. Gorski, Electrochemical sensing platform based on the carbon nanotubes/redox mediators-biopolymer system, J. Am. Chem. Soc. 127 (2005) 2058-2059.

[12] D. Du, X. Huang, J. Cai, A.D. Zhang, J.W. Ding, S.Z. Chen, An amperometric acetylthiocholine sensor based on immobilization of acetylcholinesterase on a multiwall carbon nanotube-cross-linked chitosan composite, Anal. Bioanal. Chem. 387 (2007) 1059-1065.

[13] Q.Z. Zhang, B. Zhao, J. Yan, S.P. Song, R. Min, C.H. Fan, Nanotube-based colorimetric probe for ultrasensitive detection of Ataxia Telangiectasia mutated protein, Anal. Chem. 83 (2011) 9191-9196.

[14] J.J. Gooding, R. Wibowo, J.Q. Liu, W.R. Yang, D. Losic, S. Orbons, F.J. Mearns, J.G. Shapter, D.B. Hibbert, Protein electrochemistry using aligned carbon nanotube arrays, J. Am. Chem. Soc. 125 (2003) 9006-9007.

[15] V.B. Kandimalla, H.X. Ju, Binding of acetylcholinesterase to a multiwall carbon nanotube-cross-linked chitosan composite for flow-injection amperometric detection of an organophosphorous insecticide, Chem. Eur. J. 12 (2006) 1074-1080.

[16] D. Du, J.W. Ding, J. Cai, A.D. Zhang, One-step electrochemically deposited interface of chitosan-gold nanoparticles for acetylcholinesterase biosensor design, J. Electroanal. Chem. 605 (2007) 53-60.

[17] D. Du, J.W. Ding, J. Cai, A.D. Zhang, Electrochemical thiocholine inhibition sensor based on biocatalytic growth of Au nanoparticles using chitosan as template, Sens. Actuators B: Chem. 127 (2007) 317-322.

[18] D. Du, J.W. Ding, Y. Tal, X. Cheng, Application of chemisorption/desorption process of thiocholine for pesticide detection based on acetylcholinesterase biosensor, Sens. Actuators B: Chem. 134 (2008) 908-912.

[19] G.D. Liu, Y.H. Lin, Biosensor based on self-assembling acetylcholinesterase on carbon nanotubes for flow injection/amperometric detection of organophosphate pesticides and nerve agents, Anal. Chem. 78 (2006) 835-843.

[20] S. Trasatti, O.A. Petrii, Real surface area measurements in electrochemistry, J. Electroanal. Chem. 327 (1992) 353-376.

[21] G. Tremiliosi-Filho, L.H. Dall'Antonia, G. Jerkiewicz, Limit to extent of formation of the quasi-two-dimensional oxide state on Au electrodes, J. Electroanal. Chem. 422 (1997) 149-159.

[22] S. Hrapovic, Y.L. Liu, K.B. Male, J.H.T. Luong, Electrochemical biosensing platforms using platinum nanoparticles and carbon nanotubes, Anal. Chem. 76 (2004) 1083-1088.

[23] R. Szamocki, A. Velichko, C. Holzapfel, F. Mucklich, S. Ravaine, P. Garrigue, N. Sojic, R. Hempelmann, A. Kuhn, Macroporous ultramicroelectrodes for improved electroanalytical measurements, Anal. Chem. 79 (2007) 533-539.

[24] R. Szamocki, S. Reculusa, S. Ravaine, P.N. Bartlett, A. Kuhn, R. Hempelmann, Tailored mesostructuring and biofunctionalization of gold for increased electroactivity, Angew. Chem. Int. Ed. 45 (2006) 1317-1321.
[25] C.J. Zhong, M.D. Porter, Evidence for carbon-sulfur bond cleavage in spontaneously adsorbed organosulfide-based monolayers at gold, J. Am. Chem. Soc. 116 (1994) 1616-11617.

[26] M.M. Walczak, D.D. Popenoe, R.S. Deinhammer, B.D. Lamp, C. Chung M.D. Porter, Reductive desorption of alkanethiolate monolayers at gold: a measure of surface coverage, Langmuir 7 (1991) 2687-2693.

[27] X. Yu, B. Munge, V. Patel, G. Jensen, A. Bhirde, J.D. Gong, S.N. Kim, J. Gillespie, J.S. Gutkind, F. Papadimitrakopoulos, J.F. Rusling, Carbon nanotube amplification strategies for highly sensitive immunodetection of cancer biomarkers, J. Chem. Soc. 128 (2006) 11199-11205.

[28] M. Calvaresi, F.Zerbetto, The devil and holy water: protein and carbon nanotube hybrids, Acc. Chem. Res. 46 (2013) 2454-2463.

[29] N. Chauhan, J. Narang, C.S. Pundir, Immobilization of rat brain acetylcholinesterase on porous gold-nanoparticle- $\mathrm{CaCO}_{3}$ hybrid material modified $\mathrm{Au}$ electrode for detection of organophosphorous insecticides, Int. J. Biol. Macromol. 49 (2011) 923-929

[30] D. Du, J.W. Ding, J. Cai, J.M. Zhang, L. Liu, In situ electrodeposited nanoparticles for facilitating electron transfer across self-assembled monolayers in biosensor design, Talanta 74 (2008) 1337-1343.

[31] D. Du, W.J. Chen, J. Cai, J. Zhang, F.G. Qu, H.B. Li, Development of acetylcholinesterase biosensor based on CdTe quantum dots modified cysteamine self-assembled monolayers, J. Electroanal. Chem. 623 (2008) $81-85$.

[32] D.Z. Krstić, M. Čolović, M. Bavcon kralj, M. Franko, K. Krinulović, P. Trebše, V VASIĆ, Inhibition of AChE by malathion and some structurally similar compounds, J. Enzyme Inhib. Med. Chem. 23 (2008) 562-573.

[33] C.M. Thompson, S. Ryu, C.E. Berkman, Consequence of phosphorus stereochemistry upon the postinhibitory reaction kinetics of acetylcholinesterase poisoned by phosphorothiolates, J. Am. Chem. Soc. 114 (1992) 10710-110715

[34] D.B. Liu, W.W. Chen, J.H. Wei, X.B. Li, Z. Wang, X.Y. Jiang, A highly sensitive, dual-readout assay based on gold nanoparticles for organophosphorus and carbamate pesticides, Anal. Chem. 84 (2012) 4185-4191.

[35] S.Z. Liao, Y.N. Qiao, W.T. Han, Z.X. Xie, Z.Y. Wu, G.L. Shen, R.Q. Yu, Acetylcholinesterase liquid crystal biosensor based on modulated growth of gold nanoparticles for amplified detection of acetylcholine and inhibitor, Anal. Chem. 84 (2012) 45-49.

[36] N. Chauhan, J. Narang, C.S. Pundir, Immobilization of rat brain acetylcholinesterase on $\mathrm{ZnS}$ and poly(indole-5-carboxylic acid) modified Au electrode for detection of organophosphorus insecticides, Biosens. Bioelectron. 29 (2011) 82-88

[37] N. Chauhan, C.S. Pundir, An amperometric acetylcholinesterase sensor based on $\mathrm{Fe}_{3} \mathrm{O}_{4}$ nanoparticle/multi-walled carbon nanotube-modified ITO-coated glass plate for the detection of pesticides, Electrochim. Acta 67 (2012) 79-86.

[38] G.A. Silva, F. Augusto, R.J. Poppi, Simultaneous optimization by neuro-genetic approach of amultiresidue method for determination of pesticides in Passifloraalata infuses using headspace solid phase microextraction and gas chromatography, J. Chromatogr. A 1138 (2007) 251-261.

[39] D. Du, M.H. Wang, J. Cai, J.M. Zhang, Sensitive acetylcholinesterase biosensor based on assembly of $\beta$-cyclodextrins onto multiwall carbon nanotubes for detection of organophosphates pesticide, Sens. Actuators B: Chem. 146 (2010) 337-341.

[40] S. Wu, X.Q. Lan, W. Zhao, Y.P. Li, L.H. Zhang, H.N. Wang, M. Han, S.Y. Tao, Controlled immobilization of acetylcholinesterase on improved hydrophobic gold nanoparticle/Prussian blue modified surface for ultratrace organophosphate pesticide detection, Biosens. Bioelectron. 27 (2011) 82-87.

[41] Y.H. Yang, M.M. Guo, M.H. Yang, Z.J. Wang, G.L. Shen, R.Q. Yu, Determination of pesticides in vegetable samples using an acetylcholinesterase biosensor based on nanoparticles $\mathrm{ZrO}_{2 /}$ chitosan composite film, Int. J. Environ. Anal. Chem. 85 (2005) 163-175.

[42] N. Ben Oujji, I. Bakas, G. Istamboulié, I. Ait-Ichou, E. Ait-Addi, R. Rouillon, T. Noguer, Sol-gel immobilization of acetylcholinesterase for the determination of organophosphate pesticides in olive oil with biosensors, Food Control 30 (2013) 657-661.

[43] A. Giinther, U. Bilitewsk, Characterisation of inhibitors of acetylcholinesterase by an automated amperometric flow-injection system, Anal. Chim. Acta 300 (1995) 117-125.

[44] G.A. Evtugyn, R.R. Younusov, A.N. Ivanov, R.R. Sitdikov, A.V. Galuchin, H.C. Budnikov, I.I. Stoikov, I.S. Antipin, Cholinesterase biosensors based on screen-printed electrodes modified with Co-phtalocyanine and polycarboxylated thiacalixarenes, Electroanalysis 24 (2012) $554-562$

\section{Biographies}

Jiawang Ding received his doctor's degree from Yantai Institute of Coastal Zone Research, Chinese Academy of Sciences in 2011. Presently, he is an assistant researcher in this institute. His current research interests focus on electrochemica biosensors.

Hongxia Zhang is a PhD student in Yantai Institute of Coastal Zone Research, Chinese Academy of Sciences. Her current research interests focus on bioelectrochemistry. 
Falong Jia is currently an associate professor of Central China Normal University. His research interests include the design, synthesis and applications of new materials.

Wei Qin received his doctor's degree from Nanjing University in 1998. From 1999 to 2003, he did his postdoctoral research at Swiss Federal Institute of Technology (ETH), University of South Carolina and University of Michigan, respectively. He has been working as professor at Yantai Institute of Coastal Zone Research, Chinese
Academy of Sciences since 2006. His research interests include chemical sensors and biosensors for environmental analysis.

Dan Du received her doctor's degree from Nanjing University in 2005. She is currently a professor of Huazhong Normal University. Her research interests involve biosensors and chips, electroanalytical chemistry and analysis of pesticides and biomolecules. 